\title{
Exsolution of Re-alloy catalysts with enhanced stability for methane dry reforming
}

\author{
Daria Zubenko ${ }^{1}$, Sarika Singh ${ }^{1}$, Brian A. Rosen ${ }^{1 *}$
}

1. Department of Materials Science and Engineering, Tel Aviv University, 55 Haim Levanon Street, Ramat Aviv 69987001, ISRAEL

*barosen@post.tau.ac.il

\begin{abstract}
The valorization of natural gas is a highly important process which could enable the production of hydrogen or clean synthetic fuels. Methane reforming with carbon dioxide provides an environmentally friendly route for methane conversion to synthesis gas while consuming two green-house gasses. Large-scale implementation of this process has been stalled by the lack of stable catalysts owing to variety of deactivation mechanisms such as carbon accumulation (coking) and sintering. We created doped perovskite precursors based on lanthanum ferrite $\left(\mathrm{LaFeO}_{3}\right)$ and subsequently doped them with $\mathrm{Ni}$ and Re phases. Under reducing conditions, these composite precursors exsolved Re-alloy nanoparticles which were found to be active and stable under dry reforming conditions. The solid-phase crystallization process was studied by in-situ synchrotron XRD, and compared to the temperature programmed reduction of each precursor. No carbon accumulation or nanoparticle sintering was observed after 70 hours of operation. Furthermore, the evaporation of catalytic Re phases, a major problem under reforming conditions, was shown to be completely blocked due to strong catalyst-support interactions imbued by this synthesis technique.
\end{abstract}

KEYWORDS: solid phase crystallization, rhenium, perovskites, methane dry reforming 


\section{INTRODUCTION}

The development of stable and active methane reforming catalysts has received a lot of attention due to the increasing number of natural gas discoveries worldwide. Methane, the primary component of natural gas, is a dangerous greenhouse gas, but also a potential feedstock for the production of synthetic fuels [1, 2]. The dry reforming of methane (Reaction 1) is an attractive process for natural gas valorization owing to its ability to consume two greenhouse gasses as reactants and produce synthesis gas with an $\mathrm{H}_{2}$-to-CO ratio of $1: 1$. Such a ratio is favorable for the downstream synthesis of heavy synthetic hydrocarbon fuels [3].

$\mathrm{CH}_{4}+\mathrm{CO}_{2} \leftrightarrow 2 \mathrm{CO}+2 \mathrm{H}_{2}$

Despite these advantages, large-scale utilization of methane dry reforming has been blocked due to the lack of stable catalysts under reaction conditions. Among the two largest contributors to catalyst instability are the accumulation of carbon (coking) which can block active sites and clog pores, and the sintering of active sites causing a drop in active surface area [4-6]. Rhenium ( $\mathrm{Re})$ is a common catalyst component used in the reforming industry owing to its ability to behave as both a promoter and catalyst for alkane activation [7-9]. In the case of reforming catalysts containing Re, it has been shown that rhenium phases can oxidize and subsequently sublime owing to the high vapor pressure of $\mathrm{Re}_{2} \mathrm{O}_{7}$ [10]. The sublimation of $\mathrm{Re}$ under reaction conditions not only leads to a decrease in activity, but also the loss of an expensive component of the catalyst system.

Reforming catalysts are typically prepared by various metal-on-oxide techniques such as impregnation, suspension, vapor deposition, electroless deposition, or hybrids thereof [11]. Although widely used, a potential drawback with many of these methods is the tendency for the catalyst phase to have only a superficial interaction with the support. Such a weak catalyst-support interaction can lead to the formation of carbon nanotubes (coking) via the "tip-growth" mechanism, and provides little protection against sintering or sublimation [12]

An alternative method for catalyst preparation is the use of solid-phase-crystallization. When ordered perovskite $\left(\mathrm{ABO}_{3}\right)$ frameworks are utilized as catalyst precursors, they 
have the capability of exsolving certain B-site atoms under reducing conditions through a solid-phase reaction. For example, the reduction of $\mathrm{LaNiO}_{3}$ by hydrogen leads to the formation of $\mathrm{Ni} / \mathrm{La}_{2} \mathrm{O}_{3}$, where the Ni nanoparticles are firmly "socketed" into the support thereby giving rise to a comparably strong catalyst-support interaction. The effectiveness of solid-phase-crystallization for catalyst development is highly dependent on the reducibility of the B-site cation, and more subtly on the microstructure, shape, and non-stoichiometry of the perovskite precursor [13, 14]. This technique has been extensively studied in recent years as a sustainable technique for synthesizing a wide variety of catalysts through the use of $\mathrm{LaCoO}_{3}[15,16]$, $\mathrm{LaFeO}_{3}$ [16-27], $\mathrm{LaNiO}_{3}[2,5,28-30]$ or their mixtures as precursor materials. Furthermore, the doping of these precursor structures with heteroatoms such as $\mathrm{Ru}, \mathrm{Pd}$ [20], $\mathrm{Cu}$, and $\mathrm{Mg}$ [29] has given rise to catalytic materials with enhanced activity towards methane reforming reactions. The use of Re-substituted precursors, or the creation of a composite precursor containing Re, have yet to be detailed despite the fact that $\mathrm{Re}$ is used as a co-catalyst in industrial reforming processes [31, 32].

Here, we report the use of solid-phase-crystallization in order to transform several lanthanum ferrite $\left(\mathrm{LaFeO}_{3}\right)$-based precursors containing nickel $(\mathrm{Ni})$ and/or rhenium $(\mathrm{Re})$. While $\mathrm{LaFeO}_{3}$ itself is not active, it provides high oxygen mobility and flexible redox character, properties which are instrumental in designing stable reforming catalyst [33]. The precursor materials reported in this study are $\mathrm{LaFeO}_{3}$ (LF), $\mathrm{LaNi}_{0.2} \mathrm{Fe}_{0.8} \mathrm{O}_{3} \quad(\mathrm{LNF}), \quad \mathrm{LaRe}_{\mathrm{x}} \mathrm{Fe}_{0.8} \mathrm{O}_{3+\delta^{-}} \mathrm{La}_{3} \mathrm{ReO}_{8}$ (LRF), and $\mathrm{LaNi}_{0.2} \mathrm{Re}_{\mathrm{x}} \mathrm{Fe}_{0.6} \mathrm{O}_{3+\delta^{-}}$ $\mathrm{La}_{3} \mathrm{ReO}_{8}$ (LNRF) where $\mathrm{x}<0.2$. The incorporation of heptavalent $\mathrm{Re}$ into an $\mathrm{A}^{+3} \mathrm{~B}^{+3} \mathrm{O}_{3}$ perovskite such as $\mathrm{LaFeO}_{3}$ necessarily results in an oxygen nonstoichiometry $(\delta)$ in order to maintain charge balance. It has been shown that nonstoichiometric Re substitutions in the B-site can be made to a limited extent $(<0.2)$ to form stable perovskite-like materials [34-36]. The Re that did not enter the perovskite went to form the competing $\mathrm{La}_{3} \mathrm{ReO}_{8}$ phase ultimately forming a composite precursor material. For simplicity, the shorthand naming of these materials will be used throughout the paper.

We report the structure of these precursor materials before and after solid-phase crystallization, thereby exsolving nanoparticles containing metallic $\mathrm{Ni}, \mathrm{Re}$, and some Fe which function as catalytic active sites. We describe the catalytic activity and 
stability under methane dry reforming conditions in light of gas conversion and materials characterization.

\section{EXPERIMENTAL}

\subsection{Materials Synthesis}

The catalyst precursors were prepared by the Pechini method described in detail elsewhere [28, 37]. Briefly, the solution was prepared by dissolving the desired ratio of metal precursor salts using lanthanum nitrate hexahydrate $\left(\mathrm{La}\left(\mathrm{NO}_{3}\right)_{3} \cdot 6 \mathrm{H}_{2} \mathrm{O}\right)$, iron nitrate nonahydrate $\left(\mathrm{Fe}\left(\mathrm{NO}_{3}\right)_{3} \cdot 9 \mathrm{H}_{2} \mathrm{O}\right)$ (or iron (II) oxalate dihydrate $\left(\mathrm{C}_{2} \mathrm{FeO}_{4} \cdot 2 \mathrm{H}_{2} \mathrm{O}\right)$ for Re- containing perovskites), nickel nitrate hexahydrate $\left(\mathrm{Ni}\left(\mathrm{NO}_{3}\right)_{2} \cdot 6 \mathrm{H}_{2} \mathrm{O}\right)$ and ammonium perrhenate $\mathrm{NH}_{4} \mathrm{ReO}_{4}$ in Milli-Q water. Citric acid and ethylene glycol were added in excess as complexing agents. The molar ratio of total cations, citric acid, and ethylene glycol was 1:3:3 [38]. The resulting solution was evaporated at $140^{\circ} \mathrm{C}$ on hot plate under stirring until the solution volume decreased by approximately $33 \%$. Afterwards, the temperature was reduced to $120^{\circ} \mathrm{C}$ and kept overnight to remove the solvent resulting in an aerogel. The aerogel was then ground and calcined at $400^{\circ} \mathrm{C}$ for $2 \mathrm{~h}$ and then at $700^{\circ} \mathrm{C}$ for $6 \mathrm{~h}$ in air at $1 \mathrm{~atm}$ [37].

\subsection{Materials Characterization}

Ex-situ X-ray diffraction (XRD) patterns were recorded on a Scintag powder diffractometer equipped with liquid nitrogen-cooled germanium solid state detector and using $\mathrm{Cu}-\mathrm{K} \alpha$ radiation. In-situ XRD was performed at Argonne National Laboratory's Advanced Photon Source (beamline 6ID-D) using 85.152eV (0.145586 A) synchrotron radiation. Approximately $50 \mathrm{mg}$ of sample was placed in a fused quartz capillary and mounted between two resistive heaters in a transmission X-ray cell described in detail elsewhere [39]. The 2D X-ray detector (Perkin Elmer XRD1621 CN3-EHS) was mounted approximately $1 \mathrm{~m}$ from the cell and contained a grid of 2048 x 2048 pixels (pixel size $200 \mu \mathrm{m}$ ). The incident beam size was set to $700 \mu \mathrm{m} \times 700 \mu \mathrm{m}$. Data analysis was carried out by Fit2D software and a NIST silicon 640c standard was used for calibration.

Scanning electron microscopy (SEM) and transmission electron microscopy (TEM) were performed on a Quanta 200 FEG (field-emission gun) environmental 
scanning electron microscope and field emission TEM (Tecnai ${ }^{@}$ F20, Philips) operated at $200 \mathrm{KV}$, respectively. BET surface area was measured by nitrogen adsorption at $-196^{\circ} \mathrm{C}$ using a Quantachrome ChemBET. Temperature programmed reduction (TPR) and temperature programmed oxidation (TPO) were recorded using the same instrument. Prior to BET, TPR, or TPO measurements, catalysts were degassed at $300^{\circ} \mathrm{C}$ for $1 \mathrm{~h}$ under $\mathrm{N}_{2}$ flow to remove any residual moisture, then cooled down to room temperature. For TPR and TPO measurements, fresh materials were reduced in a hydrogen mixture $\left(5 \% \mathrm{H}_{2} / \mathrm{N}_{2}\right)$ or oxidized in an oxygen mixture $\left(5 \% \mathrm{O}_{2} / \mathrm{He}\right)$ respectively, while the temperature of the furnace was increased at a heating rate of $10^{\circ} \mathrm{C} / \mathrm{min}$ to $1050^{\circ} \mathrm{C}$. Thermo-gravimetric analysis (TGA) was carried out by TGA 2950 thermogravimetric analyzer in an ambient atmosphere. XPS analysis was performed on a 5600 AES/XPS system (PHI, USA) using an Al-Ka anode $(h v=1486.6 \mathrm{eV})$ as the exciting source. The binding energies obtained in the XPS analysis were standardized for specimen charging using carbon (C 1s) as the reference at $285 \mathrm{eV}$. The conversion of methane and carbon dioxide into carbon monoxide and hydrogen was monitored using an SRI gas chromatograph fitted with MS-13X and Haysep-C packed columns. Hydrogen was detected using a nitrogen carrier and a TCD detector. $\mathrm{CO}_{2}, \mathrm{CO}$, and $\mathrm{CH}_{4}$ were detected using an argon carrier and FID detector with a methanizer placed directly upstream.

\subsection{Catalytic Activity}

Temperature programmed catalytic tests were performed by using $35 \mathrm{mg}$ of catalyst. The catalyst was placed between two pieces of quartz wool inside a 12-mm ID quartz tube $(\mathrm{L}=60 \mathrm{~mm}, \mathrm{OD}=15 \mathrm{~mm})$ in the isothermal zone of an Electrotherm tube furnace. Before catalytic testing, the sample was heated from room temperature up to $860^{\circ} \mathrm{C}$ at $20^{\circ} \mathrm{C} / \mathrm{min}$ in a $50 \% \mathrm{H}_{2} / \mathrm{Ar}(50 \mathrm{sccm})$ atmosphere and held at that temperature for $1 \mathrm{~h}$ to activate catalyst [40]. In this context, activation refers to the solid-phase crystallization process in which $\mathrm{Ni}, \mathrm{Re}$, and $\mathrm{Fe}$ atoms exsolve from the precursor to form the final catalyst material. After activation, the sample was cooled to the desired reaction temperature (variable) under Ar flow $(100 \mathrm{sccm})$ for $1 \mathrm{~h}$. The catalytic reaction was initiated by feeding mixture of methane $\left(\mathrm{CH}_{4}\right)$, carbon dioxide $\left(\mathrm{CO}_{2}\right)$, and argon (Ar) at a molar ratio of 1:1:8 with a gas hourly space velocity (GHSV) of $34,285 \mathrm{ml} /\left(\mathrm{h} \cdot \mathrm{gr}_{\mathrm{cat}}\right)$. A stability test, where the catalyst was held at a 
constant temperature for an extended period of time, were performed in the same way as described above.

\section{RESULTS AND DISCUSSION}

\subsection{Catalyst Precursor Characterization}

$\mathrm{X}$-ray diffraction (XRD) was used to determine the phase composition of all four precursor materials and is shown in Figure 1. The XRD patterns of the $\mathrm{LaFeO}_{3}(\mathrm{LF})$ precursor revealed the formation of a highly crystalline single-phase perovskite with an orthorhombic structure (JCPDS 02-8255). The partial B-site substitution of Fe by $\mathrm{Ni}$ to make $\mathrm{LaNi}_{0.2} \mathrm{Fe}_{0.8} \mathrm{O}_{3}$ (LNF) gave rise to a shift in the diffraction peaks to higher values of $2 \theta$. Figure S1 shows that the (112) peak position of LNF is shifted to higher $2 \theta$ compared to the (112) peak of $\mathrm{LaFeO}_{3}\left(32.17^{\circ}\right)$ but not as high as the corresponding $\mathrm{LaNiO}_{3}$ peak at 33.14 (JCPDS 33-0714). This suggests that structure of $\mathrm{LNF}$ is a $0.8-\mathrm{LaFeO}_{3} / 0.2-\mathrm{LaNiO}_{3}$ solid solution [41, 42].

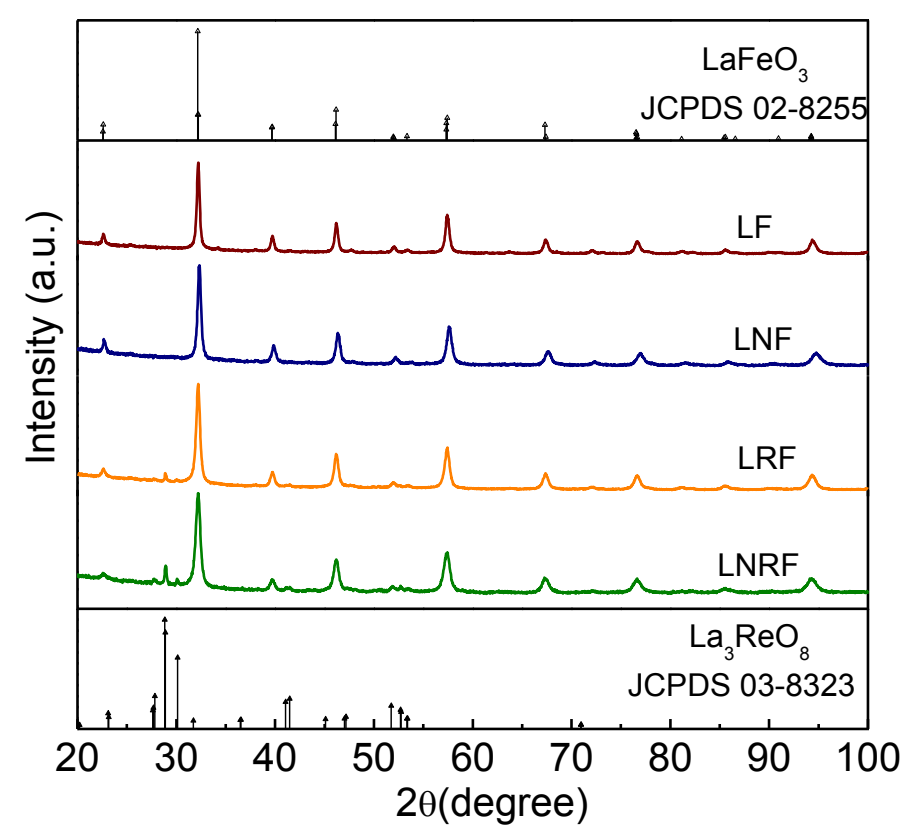

Figure 1: XRD patterns of all four synthesized precursors along with the JCPDS entry for $\mathrm{LF}$ and $\mathrm{La}_{3} \mathrm{ReO}_{8}$. Substitution of $\mathrm{Ni}$ and/or Re did not destroy the underlying LF structure. Precursors with Re contained a small amount of $\mathrm{La}_{3} \mathrm{ReO}_{8}$ contaminant.

The partial B-site substitution of Re into LF and $\mathrm{LNF}$ gave $\mathrm{LaRe}_{\mathrm{x}} \mathrm{Fe}_{0.8} \mathrm{O}_{3+\delta}-\mathrm{La}_{3} \mathrm{ReO}_{8}$ (LRF) and $\mathrm{LaNi}_{0.2} \mathrm{Re}_{\mathrm{x}} \mathrm{Fe}_{0.6} \mathrm{O}_{3+\delta}-\mathrm{La}_{3} \mathrm{ReO}_{8}$ (LNRF) respectively. Despite the oxygen non-stoichiometry of these Re-included perovskites, XRD confirms that the 
substitution of Re did not destroy the underlying perovskite structure of the parent $\mathrm{LaFeO}_{3}$ material.

As a consequence of the non-stoichiometry for Re-included precursors, the competitive phase $\mathrm{La}_{3} \mathrm{ReO}_{8}$ (JCPDS 03-8323) was also formed, giving rise to a multiphase precursor. An increase in the full-width at half-maximum (FWHM) of the diffraction peaks was observed as the extent of substitution increased ( $\mathrm{LF}<\mathrm{LRF} \sim \mathrm{LNF}<\mathrm{LNRF}$ ), attributable to the decrease in crystalline size. Partial substitution into the perovskite lattice can induce minor structural disorder thereby hindering crystallite growth and leading to smaller crystal sizes [43]. The extent of increasing disorder can also be seen by SEM micrographs of fresh LF, LNF, LRF, and LNRF in Figure 2. While all samples had approximately the same macrostructure, the porosity appeared to increase with the extent of substitution. This observation is consistent with the BET results giving 6.4, 9.0, 15.7 and $24.3 \mathrm{~m}^{2} / \mathrm{g}$ for LF, LNF, LRF and LNRF respectively.

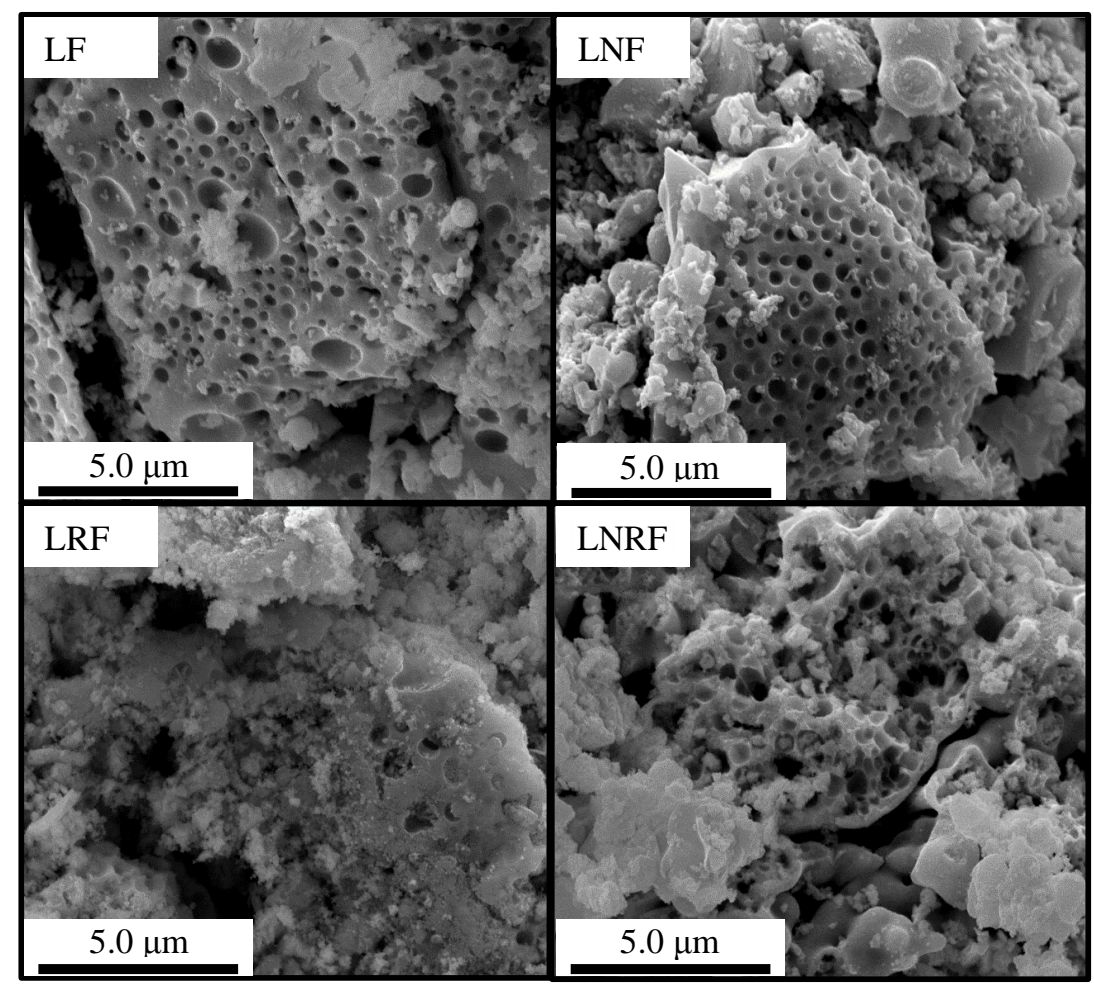

Figure 2: SEM micrographs of fresh LF, LNF, LRF, LNRF precursors. 


\subsection{Solid-Phase Crystallization of the Precursors}

All four perovskite precursors were activated by exposure to $50 \%$ hydrogen at $860^{\circ} \mathrm{C}$ for $1 \mathrm{hr}$. This reduction treatment gave rise to the destabilization of the precursor via the solid-phase crystallization process. As a result, B-site cations were reduced and exsolved to form nanoparticles dispersed on a support containing $\mathrm{La}_{2} \mathrm{O}_{3}$ and LF. The temperature of this transformation and the composition of the exsolved nanoparticles depended on the composition of the precursor. In order to obtain information about the solid-phase crystallization process, temperature programmed reduction in $5 \% \mathrm{H}_{2} / \mathrm{N}_{2}$ (TPR) was performed. The uptake in hydrogen can be indicative of the solid-phase reduction processes required to form the final catalyst. The TPR reduction profiles of LF, LNF, LRF and LNRF are shown in Figure 3. It is well known that the complete reduction of $\mathrm{Fe}^{3+}$ to $\mathrm{Fe}^{0}$ usually occurs only at high temperatures $\left(>900^{\circ} \mathrm{C}\right)$ owing to the strength of the $\mathrm{Fe}-\mathrm{O}$ bond.

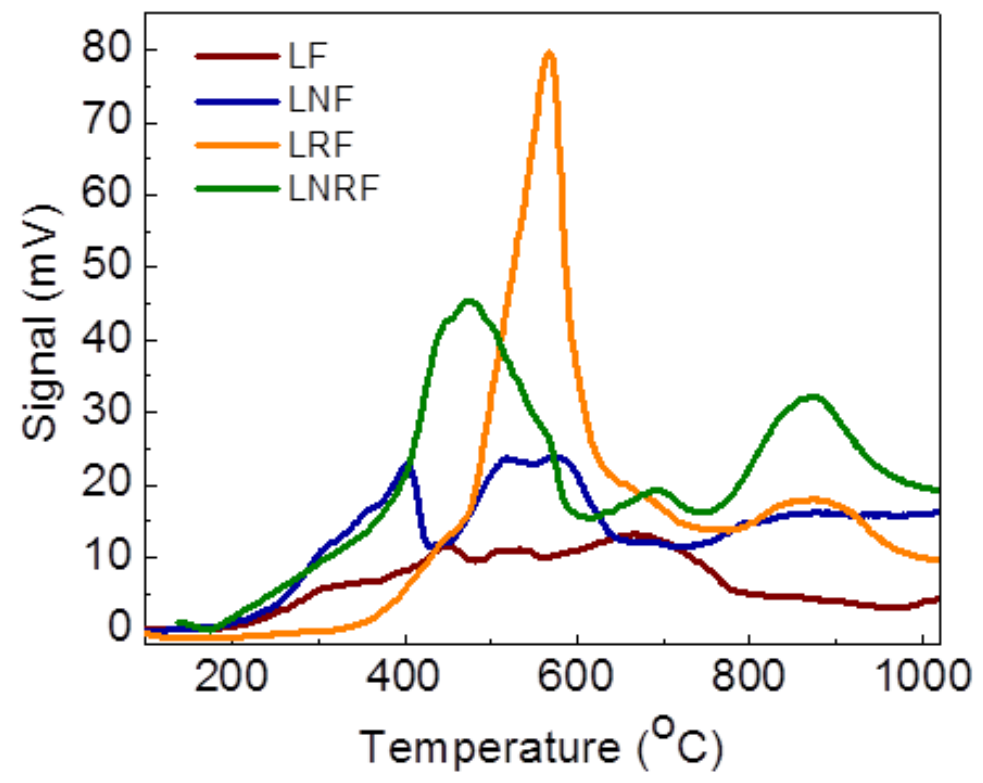

Figure 3: TPR profiles of LF, LNF, LRF, and LNRF.

The final calcination step required to make LF can lead to a small fraction of $\mathrm{Fe}$ cations oxidizing to the less stable $\mathrm{Fe}^{+4}$ state [44]. The resulting LF material would then show a slight oxygen excess $\mathrm{LaFe}_{x}^{+4} \mathrm{Fe}_{1-x}^{+3} \mathrm{O}_{3+\delta}$ to maintain neutrality. The peaks between $350-560^{\circ} \mathrm{C}$ are therefore attributed to the reduction of absorbed $\alpha$ oxygen and reduction of $\mathrm{Fe}^{4+}$ to $\mathrm{Fe}^{3+}$ [45]. The broad peak between $560-800^{\circ} \mathrm{C}$ is 
attributed to reduction of $\mathrm{Fe}^{+3}$ to $\mathrm{Fe}^{+2}$, giving rise to a partially reduced $\mathrm{LF}$ [46]. The TPR profile of the LNF sample consisted of three peaks, the first peak centered at $395^{\circ} \mathrm{C}$ is possibly attributed to the reduction of $\mathrm{LaNiO}_{3}$ component of $\mathrm{LNF}$ to $\mathrm{La}_{4} \mathrm{Ni}_{3} \mathrm{O}_{10}$ based on previous work by us and others [30, 47]. The second peak centered at $575^{\circ} \mathrm{C}$ is a convolution of the reduction of $\mathrm{La}_{4} \mathrm{Ni}_{3} \mathrm{O}_{10}$ to $\mathrm{La}_{2} \mathrm{NiO}_{4}$, and the subsequent reduction of $\mathrm{La}_{2} \mathrm{NiO}_{4}$ to $\mathrm{Ni}^{0}$, along with the reduction of $\mathrm{Fe}^{+4}$ and $\alpha$ oxygen reduction seen in LF. The third peak, centered at $850^{\circ} \mathrm{C}$ and not present in the LF sample, is the result of small amounts of $\mathrm{Fe}^{0}$ exsolving in the form of a $\mathrm{Ni}-\mathrm{Fe}$ alloy as shown by TEM-EDX in Figure S2. This is likely due to the fact that Nisubstitution weakens the Fe-O bond allowing the co-exsolution of small amount of metallic Fe with $\mathrm{Ni}$ at temperatures where $\mathrm{Fe}$ in the pure LF structure could not be reduced.

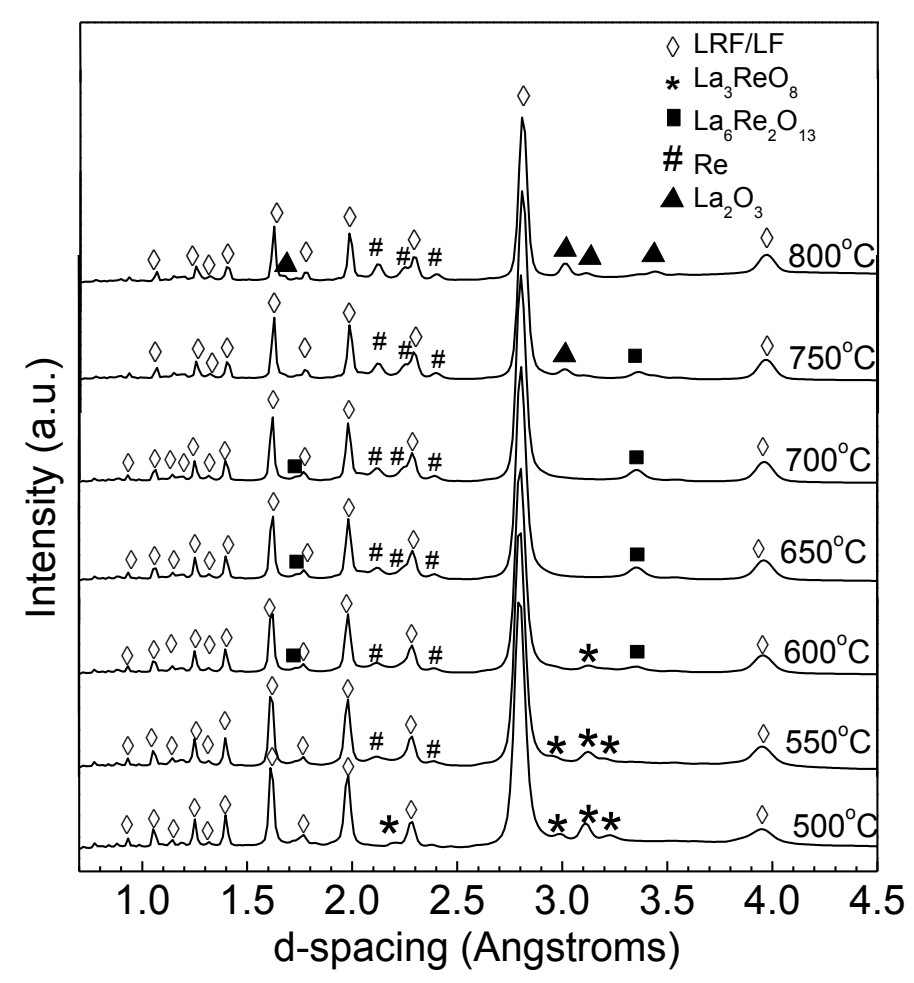

Figure 4: In-situ synchrotron XRD patterns of LRF at $500-800^{\circ} \mathrm{C}$ under $3 \% \mathrm{H}_{2} / \mathrm{Ar}$ reducing atmosphere.

In contrast to LNF reduction, the reductions of LRF and LNRF were more complex and have not been previously reported. We therefore studied the reduction of these two compounds using synchrotron radiation XRD in transmission mode under a flow 
of $3 \% \mathrm{H}_{2} / \mathrm{N}_{2}$. For convenience, diffractograms from synchrotron radiation $(85.152 \mathrm{eV}$, $0.145586 \AA$ ) are reported in terms of d-spacing. TPR of LRF from Figure 3 shows that the precursor exhibited two main reduction peaks centered at $570^{\circ} \mathrm{C}$ and $870^{\circ} \mathrm{C}$.

Figure 4 shows in-situ reduction of LRF measured by synchrotron radiation XRD. No significant phase transition is noticeable in the $\mathrm{XRD}$ until $500^{\circ} \mathrm{C}$, suggesting the original phases were stable up to this temperature. The fact that hydrogen uptake began at a slightly lower temperature $\left(\sim 450^{\circ} \mathrm{C}\right)$ in the TPR can be attributed to small kinetic differences, as the hydrogen concentration in the XRD experiment was lower. At $550{ }^{0} \mathrm{C}$, we observed the beginning of Re exsolution from the appearance of metallic Re peaks. At $600^{\circ} \mathrm{C}$, the $\mathrm{La}_{3} \mathrm{ReO}_{8}$ component began to undergo reduction to $\mathrm{La}_{6} \mathrm{Re}_{2} \mathrm{O}_{13}$ via the proposed reaction:

$2 \mathrm{La}_{3} \mathrm{ReO}_{8}+3 \mathrm{H}_{2} \rightarrow \mathrm{La}_{6} \mathrm{Re}_{2} \mathrm{O}_{13}+3 \mathrm{H}_{2} \mathrm{O}$

We therefore suggest that at $650^{\circ} \mathrm{C}$, Re exists in at least two oxidation states: mostly $\mathrm{Re}^{+4}$ (from $\mathrm{La}_{6} \mathrm{Re}_{2} \mathrm{O}_{13}$ ), and metallic Re. The existence of rhenium in multiple oxidation states as suggested here has been previously reported by us and others [48, 49]. Between $650^{\circ} \mathrm{C}$ and $800^{\circ} \mathrm{C}$, XRD shows that $\mathrm{La}_{6} \mathrm{Re}_{2} \mathrm{O}_{13}$ is reduced to form lanthanum oxide and additional metallic Re. The second major reduction peak of LRF centered at $850^{\circ} \mathrm{C}$ means that there must be reducible material remaining after at $800^{\circ} \mathrm{C}$, yet XRD shows no clear reducible species. It is possible that some reducible heptavalent rhenium remains in the precursor at this temperature. It was previously reported that oxiphilic $\mathrm{Re}^{+7}$ can form different types of bonds with lattice oxygen within the perovskite matrix [48]. TPR results here suggest that $\operatorname{Re}^{+7}$ with weaker bonds are reduced to metallic Re below $800{ }^{0} \mathrm{C}$, while $\mathrm{Re}^{+7}$ with stronger bonds may be reduced only above $800{ }^{\circ} \mathrm{C}$.

It is immediately clear that the TPR curve of LNRF is not simply a linear combination of LNF and LRF. The TPR profile of LNRF consists of three large peaks centered at $470^{\circ} \mathrm{C}, 690^{\circ} \mathrm{C}$ and $870^{\circ} \mathrm{C}$. In-situ XRD for LNRF reduction is shown in Figure 5.

The first significant phase transformation is observed by $\mathrm{XRD}$ at $500^{\circ} \mathrm{C}$ with the formation of the $\mathrm{La}_{6} \mathrm{Re}_{2} \mathrm{O}_{13}$ phase. The absence of XRD peaks related to the partially reduced nickel phases (e.g. $\mathrm{Ni}^{+2}$ ) may be due to their small concentration, small size, or the similarity in d-spacing with $\mathrm{La}_{2} \mathrm{NiO}_{4}$ (PDF 04-001-7966) and the LNRF 
perovskite. Despite this, the position and shape of the TPR profile compared to previous work on in-situ $\mathrm{LaNiO}_{3}$ reduction [30] make it clear that the first TPR peak of LNRF is attributable to both $\mathrm{Ni}^{+3}$ reduction to $\mathrm{Ni}^{+2}$, as well as $\mathrm{Re}^{+7}$ reduction to $\mathrm{Re}^{+4}$.

The second peak of LNRF sample in TPR (centered at $690^{\circ} \mathrm{C}$ ) is understood by XRD (between $650^{\circ} \mathrm{C}$ to $800^{\circ} \mathrm{C}$ ) as the $\mathrm{La}_{6} \mathrm{Re}_{2} \mathrm{O}_{13}$ and $\mathrm{La}_{2} \mathrm{NiO}_{4}$ phases reducing to form a tri-metallic Re-Ni-Fe phase and $\mathrm{La}_{2} \mathrm{O}_{3}$. The XRD peaks from metallic Re crystallized from LNRF are shifted to lower d-spacing compared to their position in reduced LRF, indicating the formation of an alloy phase with significant amounts of Ni. While TEM supports the presence of small amounts of $\mathrm{Fe}$ in the exsolved particle, its contribution is too small to be determined by XPS or XRD if it is metallic. The third reduction peak of LNRF appears identical to the LRF case.

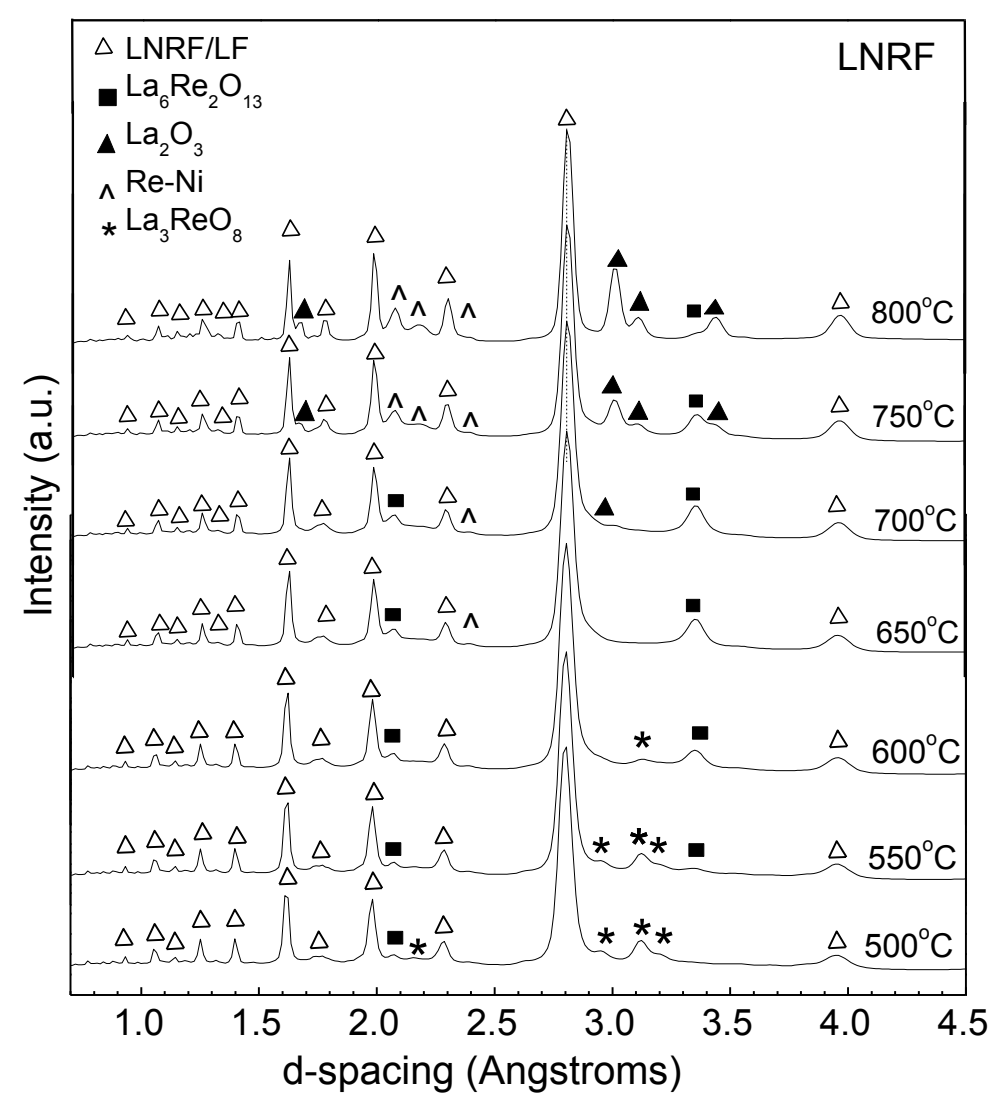

Figure 5: In-situ synchrotron XRD patterns of $\mathrm{LNRF}$ at $500-800^{\circ} \mathrm{C}$ under $3 \% \mathrm{H}_{2} / \mathrm{Ar}$ reducing atmosphere.

In-situ XRD and TPR showed that the solid-phase crystallization destroyed the original perovskite phase and exsolved metallic Ni-Fe (from LNF), Re-Fe (from LRF) 
and Ni-Re-Fe (from LNRF) phases dispersed on a $\mathrm{LaFeO}_{3} / \mathrm{La}_{2} \mathrm{O}_{3}$ support. We believe that the ability of $\mathrm{Ni}$ and $\mathrm{Re}$ (which are easily reducible) to impact the reducibility of Fe within the precursor structure, along with mutual solubility between $\mathrm{Ni}, \mathrm{Re}$, and $\mathrm{Fe}$, gave rise to alloy formation as opposed to nanoparticles of $\mathrm{Ni}, \mathrm{Re}$, and $\mathrm{Fe}$ exsolving separately.

In principle, the exsolution of multiple metals as described here could give rise several possible catalyst configurations depending on the type of multi-metallic exsolution. For example, the generalized precursor $\mathrm{LaB}_{\mathrm{x}} \mathrm{B}_{(1-\mathrm{x})}^{\prime} \mathrm{O}_{3}$ could exsolve nanoparticles of $\mathrm{B}$ and $\mathrm{B}^{\prime}$ on an $\mathrm{La}_{2} \mathrm{O}_{3}$ support in several possible configurations as listed below and illustrated schematically in Figure 6.

1. B and B' nanoparticles exsolve spatially separate from one another

2. B and B' exsolve as separate nanoparticles but with a shared interface

3. B-B' alloy nanoparticles are exsolved

Understanding which category the final catalyst material falls into is highly important for the design of advanced catalyst materials. If $\mathrm{B}$ and $\mathrm{B}$ are mutually soluble, it is most likely that B-B' alloy nanoparticles will be formed as was observed in this study. In principle, the factors that may lead to non-alloyed configurations include miscibility and reducibility. In the later case, a temperature ramp could be used to first exsolve nanoparticles of the easily reducible metal, and the metal which is more difficult to reduce would exsolve in a separate process at higher temperatures. If B and $\mathrm{B}^{\prime}$ are meant to perform independent catalytic functions, then option 1 may be preferred. If $\mathrm{B}$ and $\mathrm{B}^{\prime}$ are meant to perform catalytic functions that occur in series, then option 2 may be preferred, and if one wishes to modify the electronic nature of the active site for enhanced catalytic activity (as was the case here), option 3 may be preferred. There is not yet a comprehensive understanding on how to know ab initio which precursor will yield which configuration. 


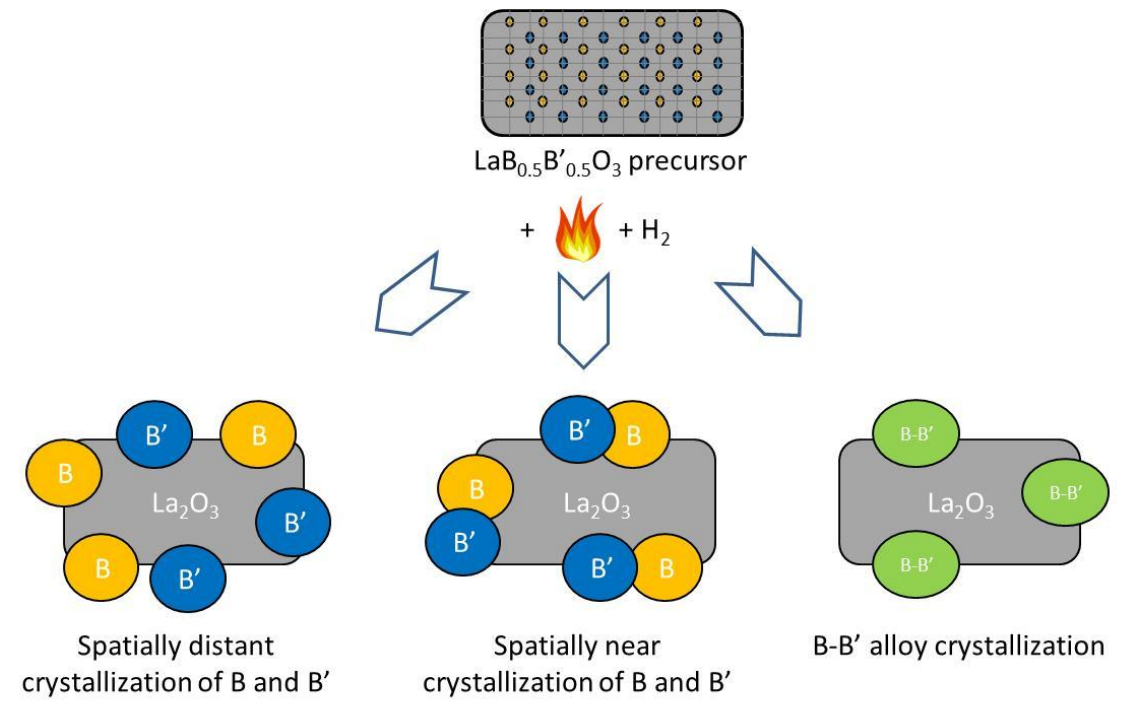

Figure 6: Schematic illustration for the possible geometries of co-exsolution of $\mathrm{B}$ and $\mathrm{B}^{\prime}$ from an ordered ceramic precursor $\mathrm{LaB}_{0.5} \mathrm{~B}_{0.5}^{\prime} \mathrm{O}_{3}$.

\subsection{Catalytic Activity for Methane Dry Reforming}

The catalyst material derived from each precursor after solid-phase crystallization was measured in order to investigate the effect of $\mathrm{Ni}$ and $\mathrm{Re}$ addition to the precursor material on the activity and stability under dry reforming conditions. The temperaturedependent conversion $\left(750-900^{\circ} \mathrm{C}\right)$ of $\mathrm{CH}_{4}$ and $\mathrm{CO}_{2}$, as well as the $\mathrm{H}_{2}: \mathrm{CO}$ product ratio are shown in Figure 7. The total carbon balance for the system came to $>99 \%$ which is within the measurement error of the TCD and FID detectors.

While LF has been suggested to provide stability to methane dry reforming catalysts owing to its redox character, it is itself a poor catalyst $[41,50]$. Ni, however, is an excellent catalyst for methane reforming owing to its ability to activate the $\mathrm{C}-\mathrm{H}$ bond. As a result, exsolving $\mathrm{Ni}-\mathrm{Fe}$ nanoparticles during the activation process led to a significant rise in catalytic activity compared to LF. The activity of the catalyst derived from LNF here is lower than catalysts derived from $\mathrm{LaNiO}_{3}$ reported by us and others $[2,30]$ owing to the lower Ni concentration; however, these LNF derived catalysts show a higher stability against carbon accumulation [40]. 

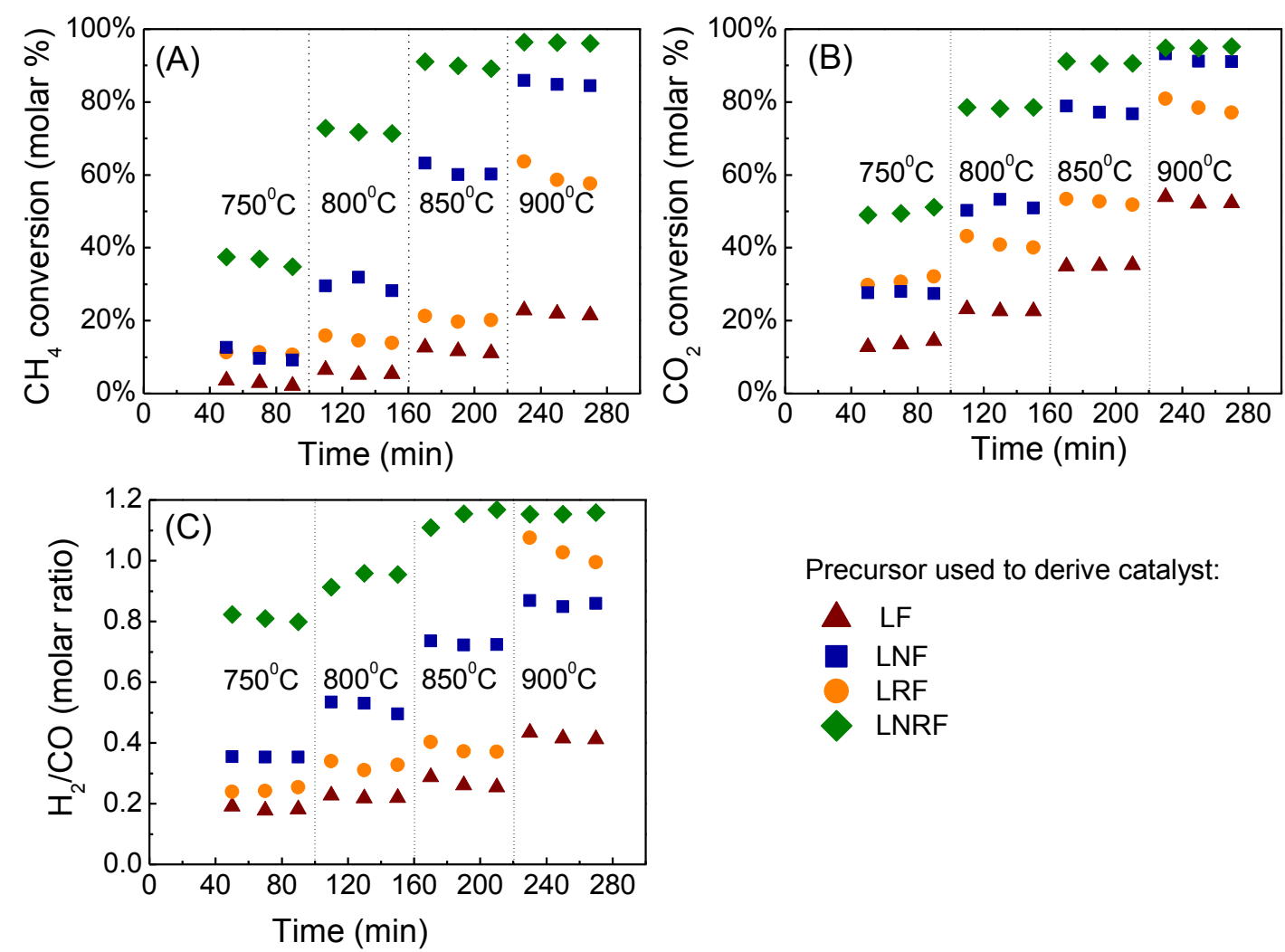

Precursor used to derive catalyst:

$\triangle \mathrm{LF}$

- LNF

LRF

LNRF

Figure 7: Catalytic conversion of methane (A), carbon dioxide (B), and product ratio (C) on catalysts derived from LF, LNF, LRF, and LNRF precursors at different operating temperatures.

Compared to the catalytic activity of the Ni-Fe particles, the exsolution of $\mathrm{Re}-\mathrm{Fe}$ nanoparticles from LRF proved to be less catalytic, and only showed a significant increase in methane conversion at $900^{\circ} \mathrm{C}$. While a majority of metallic Re was found to exsolve by $800^{\circ} \mathrm{C}$ in a reducing atmosphere, the composition of the gas stream under dry reforming conditions contains both oxidizing $\left(\mathrm{CO}_{2}\right)$ and reducing $\left(\mathrm{CH}_{4}\right.$, $\mathrm{CO}, \mathrm{H}_{2}$ ) agents. Figure 8 shows three temperature programmed experiments done in series, TPR-TPO-TPR (the second TPR is labeled "post-TPR"). In the case of LRF and LNRF, once the exsolved Re oxidized (here via the TPO process), its subsequent reduction back to metallic Re is shifted to higher temperatures by nearly 100 degrees. A majority of the metallic Re may therefore only be stable at higher $\left(\sim 900^{\circ} \mathrm{C}\right)$ temperatures when an oxidizing agent is also present. 

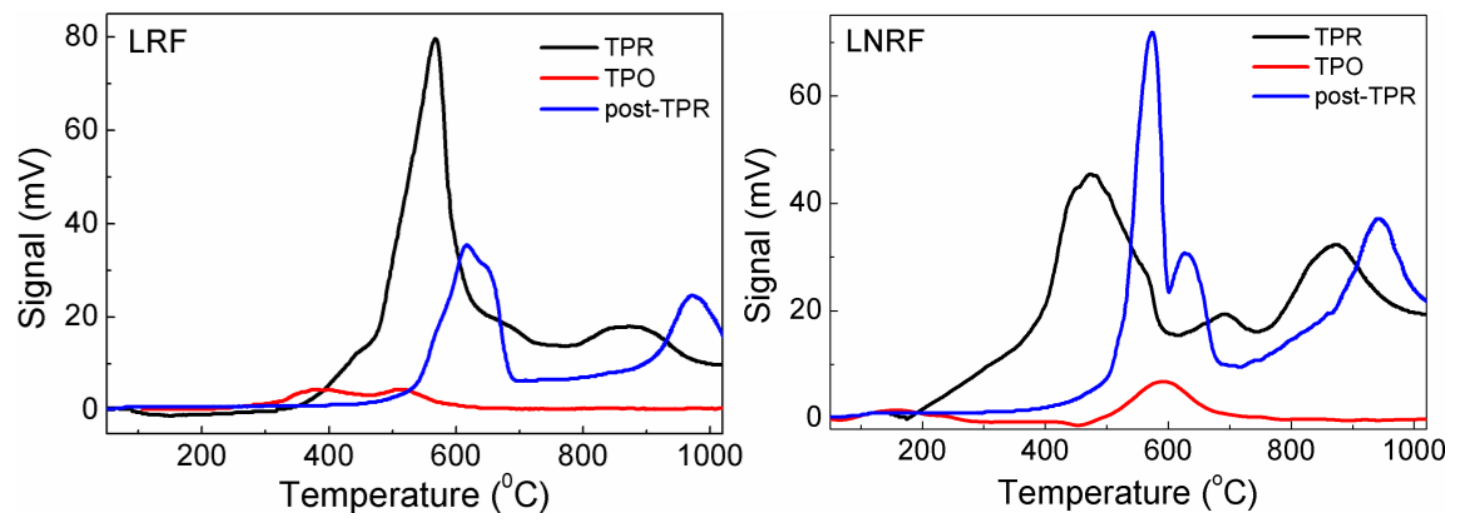

Figure 8: Temperature programmed experiments showing differences in the reducibility of rhenium-containing phases before and after an oxidation cycle.

Catalyst derived from LNRF showed the best activity at all studied temperatures by a significant margin. Even at $750^{\circ} \mathrm{C}$, the presence of $\mathrm{Re}$ within the $\mathrm{Ni}-\mathrm{Fe}$ nanoparticles greatly enhanced the conversion. Catalysts derived from LNRF also acted to repress the influence of the reverse water-gas shift reaction (Reaction 3), a common side reaction, which acts to lower the $\mathrm{H}_{2}$ : $\mathrm{CO}$ ratio below unity.

$\mathrm{CO}_{2}+\mathrm{H}_{2} \leftrightarrow \mathrm{CO}+\mathrm{H}_{2} \mathrm{O}$

The LNF, LRF, and LNRF derived catalysts also appeared to be more stable than similar lanthanum-based precursors substituted with $\mathrm{Cu}, \mathrm{Co}$, and $\mathrm{Cr}-$ all of which showed significant carbon accumulation in the form of MWNTs after 24 hours of dry reforming [46]. The stability of catalysts derived from all four precursors was evaluated at $800^{\circ} \mathrm{C}$ for a period of 30 hours and presented in Figure S3. Stability can be broken down into three categories: (a) resistance against carbon accumulation, (b) resistance against sintering, and in the case of Re catalysts, (c) resistance against $\mathrm{Re}$ sublimation. TEM of spent catalyst in Figure 9 and thermographic analysis revealed no carbon accumulation (typically found in the form of multi-walled carbon nanotubes or graphite [51, 52]) after 30 hours of operation. This result is corroborated by temperature programmed oxidation and reduction of spent catalysts which further revealed no carbon accumulation. 

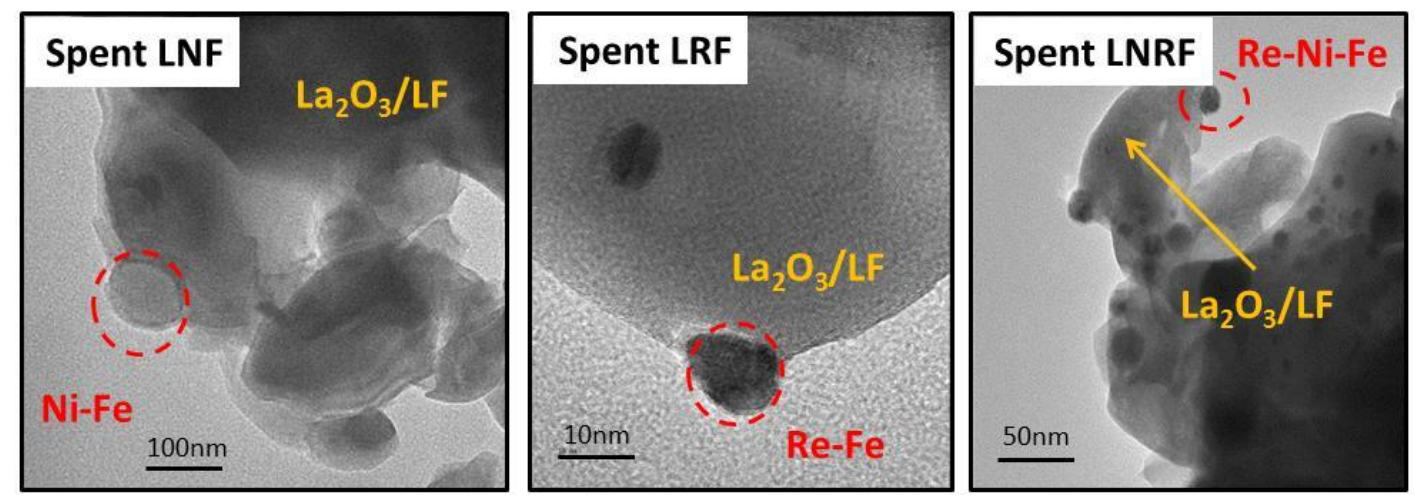

Figure 9: TEM images of spent catalysts derived from LNF, LRF, and LNRF precursors after 30 hours of operation at $800^{\circ} \mathrm{C}$.

The average size of Ni-Fe, Re-Fe and Re-Ni-Fe nanoparticles (exsolved from LNF, LRF, and LNRF respectively) was measured by TEM image analysis of $~ 100$ particles and found to be 51.9, 13.3 and $23.1 \mathrm{~nm}$ respectively. The average nanoparticle size did not change after 70 hours of reaction, leading us to the conclusion that there was no appreciable sintering in this timeframe. The structure of the LF phase did not change after catalytic testing, confirming the stability of the $\mathrm{LaFeO}_{3}$ support phase. The only appreciable difference was the decrease in the FWHM of the LF peaks, meaning the material became more crystalline after exposure to high temperatures. XRD of spent LNF in Figure S4 shows the shifting of the (112) diffraction peak to the expected position for $\mathrm{LF}$, confirming that $\mathrm{Ni}$ ions were reduced and exsolved from the LNF lattice leaving behind LF.

XPS of fresh and spent catalysts derived from LF, LNF, LRF, and LNRF samples are shown in Figure S5. Spent catalyst from LNF, LRF, and LNRF consisted of a shoulder at $706.7 \mathrm{eV}$ due to presence metallic Fe as supported by TEM-EDX, although the amount of $\mathrm{Fe}$ in the Re-containing catalysts appears smaller. The Re4f spectrum of fresh LRF and LNRF split into two peaks positioned at about 47.8 and $46.1 \mathrm{eV}$ revealing the presence of only $\operatorname{Re}^{+7}$ [53]. Spent LRF and LNRF exhibited two features in the Re4f spectrum. The first is a broad feature covering $42-51 \mathrm{eV}$ and is indicative of Re present in multiple oxidation states since clear splitting is no long observed [31, 32]. The second peak at $40.95 \mathrm{eV}$ is associated with metallic $\operatorname{Re}$ [54]. By comparing the Re4f spectrum of spent LRF and LNRF, we found that the metallic Re peak in LNRF is shifted to higher binding energy, supporting the formation of Realloy nanoparticles during the exsolution process. 
One of the major advantages of the solid-phase exsolution technique described here is that the resulting nanoparticles are firmly socketed into the support, giving rise to a large interfacial area and a strong catalyst-support interaction $[13,14,30]$. The large interfacial area giving rise to the "socketing" geometry is seen clearly in Figure 10.
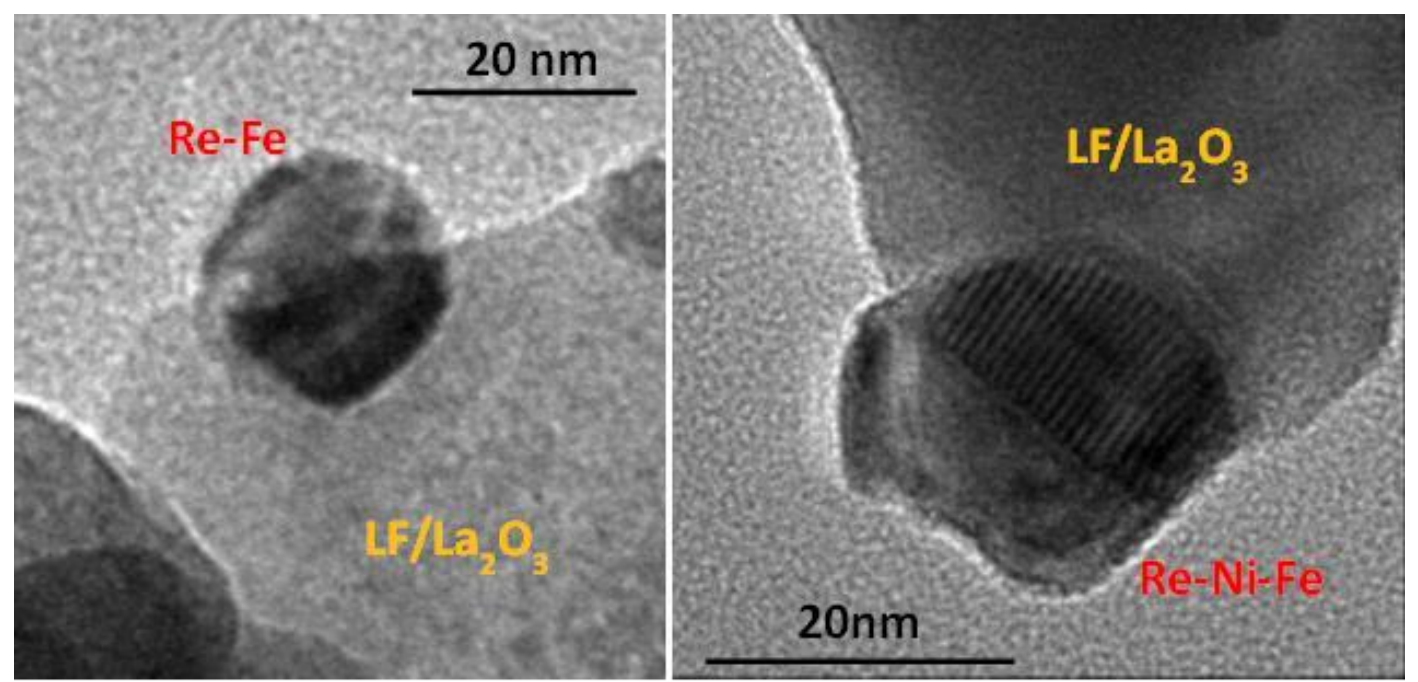

Figure 10: Bright-field TEM micrographs showing how the alloyed nanoparticles are firmly "socketed" into their supports - lending to high stability.

This interaction gives rise to stability, and has proven to prevent the sublimation of rhenium oxide phases, a common problem in reforming catalysts.

Figure 11 shows the quartz tube housing for the use of two different types of $\mathrm{Ni}_{0.5} \mathrm{Re}_{0.5}$ catalysts. The tube in the top image resulted from the use of an electrodeposited $\mathrm{Ni}_{0.5} \mathrm{Re}_{0.5}$ catalyst phase under reforming conditions $\left(800^{\circ} \mathrm{C}\right)$ for 24 hours, while the bottom resulted from the use of a $\mathrm{Ni}_{0.5} \mathrm{Re}_{0.5}$ phase (with a small amount of $\mathrm{Fe}$ ) derived from solid-phase crystallization of LNRF. The deposited $\mathrm{Ni}_{0.5} \mathrm{Re}_{0.5}$ catalyst began to sublime and gave rise to a black (Ni) and blue (Ni-Re) films deposited on the inside of the quartz tube. Owing to the strong catalyst-support interactions, Re-based catalysts derived from solid-phase crystallization showed no sublimation under identical conditions after 3 times the reaction duration. 


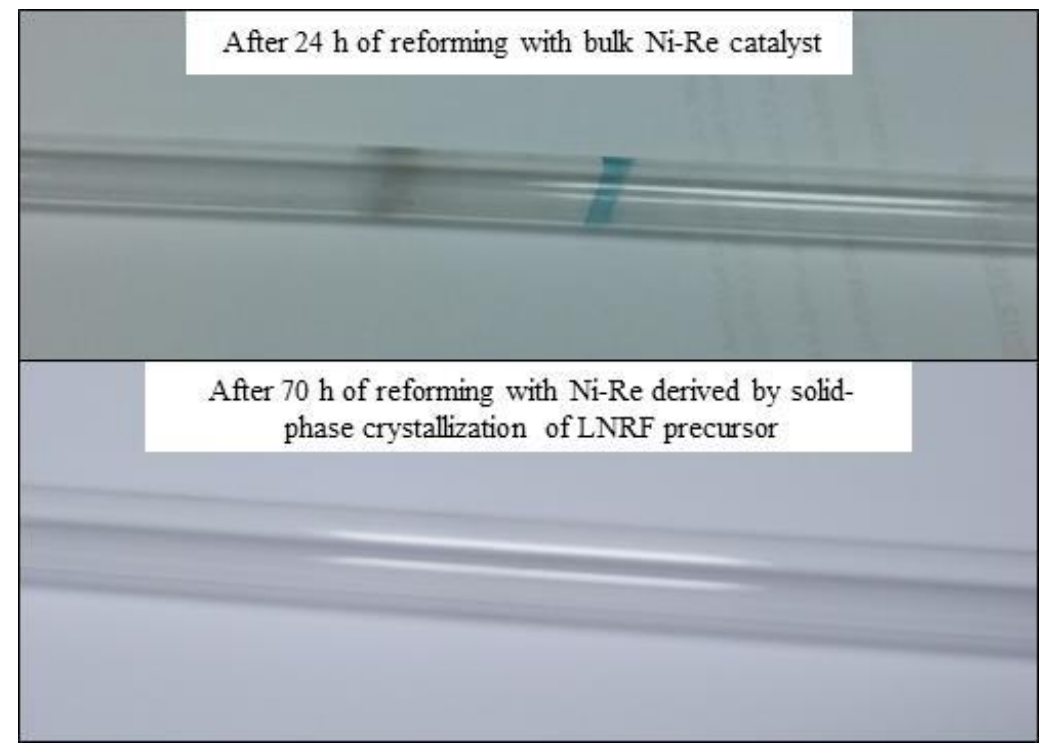

Figure 11: Quartz tube reactors after methane dry reforming at $800^{\circ} \mathrm{C}$ utilizing either a deposited $\mathrm{Ni}-\mathrm{Re}$ phase or a $\mathrm{Ni}-\mathrm{Re}$ phase grown using solid-phase crystallization.

Solid-phase crystallization could therefore be a sustainable and simple method for preparing volatile catalyst phases that would otherwise evaporate under reaction conditions leading to a loss of material and catalytic activity.

\section{Conclusions}

Re and $\mathrm{Ni}$ were successfully added to the $\mathrm{LaFeO}_{3}(\mathrm{LF})$ perovskite structure forming either a substituted perovskite or a composite precursor material. Despite the fact that some of the $\mathrm{Re}$ went to form $\mathrm{La}_{3} \mathrm{ReO}_{8}$, this secondary phase was distributed evenly throughout the precursor and lead to the formation of alloy nanoparticles. Solid phase crystallization of these precursors gave rise to $\mathrm{Ni}-\mathrm{Fe}, \mathrm{Re}-\mathrm{Fe}$, and $\mathrm{Re}-\mathrm{Ni}-\mathrm{Fe}$ nanoparticles which were shown by TEM to be firmly socketed into a $\mathrm{La}_{2} \mathrm{O}_{3} / \mathrm{LF}$ support. While Re nanoparticles were not highly active until $900^{\circ} \mathrm{C}$, the activity of $\mathrm{Ni}$ nanoparticles was enhanced by the addition of Re even at low temperatures. The catalyst derived from the solid-phase crystallization of LNRF was found to be highly promising toward applications in the dry reforming process, since carbon accumulation, nanoparticle sintering, and evaporation of the Re-containing phases was restricted due to the strong catalyst-support interaction given by the in-situ growth process. 


\section{SUPPLEMENTARY INFORMATION}

The (112) diffraction peak of all four precursors, TEM-EDX line scans of LNF and LNRF, XRD, and XPS of each catalyst before and after 30 hours of dry reforming can be found in the supplementary information.

\section{AUTHOR CONTRIBUTIONS}

DZ collected all of the catalytic and $e x$-situ data with assistance from SS. BAR and SS drafted the manuscript with critical comments provided by DZ. BAR and SS collected all synchrotron data, while DZ and SS performed the analysis.

\section{ACKNOWLEDGEMENTS}

This research was funded by the Israeli Ministry of Infrastructures, Energy and Water Resources (grant\# 215-11-033). SS would like to thank the Israeli Council for Higher Education for partial support. The authors want to thank Dr. Yuri Rosenberg for collection of the ex-situ XRD data and for assistance in interpreting in-situ synchrotron XRD data, Dr. Douglas Robinson (APS) for his help in collecting the synchrotron data. The authors want to thank and acknowlege the Advanced Photon Source (APS) at Argonne National Laboratory for enabling our in-situ XRD study (GUP-47579). The authors wand to thank Dr. Larissa Burstein for collection of the XPS data, Dr. George Levi and Prof. Amit Kohn and Dr. Vladamir Ezersky (BGU) for assistance with TEM imaging, and Prof. Noam Eliaz for the use of laboratory space. The authors also want to thank Gil Hayoun for assisting with the construction of the experimental assemblies.

\section{References:}

[1] D. Pakhare, J. Spivey, A review of dry (CO 2) reforming of methane over noble metal catalysts, Chemical Society Reviews, 43 (2014) 7813-7837. 
[2] X. Li, D. Li, H. Tian, L. Zeng, Z.-J. Zhao, J. Gong, Dry reforming of methane over Ni/La2O3 nanorod catalysts with stabilized Ni nanoparticles, Applied Catalysis B: Environmental, 202 (2017) 683-694.

[3] S. Wang, G. Lu, G.J. Millar, Carbon dioxide reforming of methane to produce synthesis gas over metal-supported catalysts: state of the art, Energy \& Fuels, 10 (1996) 896-904.

[4] C.j. Liu, J. Ye, J. Jiang, Y. Pan, Progresses in the Preparation of Coke Resistant Ni-Based Catalyst for Steam and CO2 Reforming of Methane, ChemCatChem, 3 (2011) 529-541.

[5] G.S. Gallego, C. Batiot-Dupeyrat, J. Barrault, E. Florez, F. Mondragon, Dry reforming of methane over $\mathrm{LaNi} 1-$ y $\mathrm{B}$ y $\mathrm{O} 3 \pm \delta(\mathrm{B}=\mathrm{Mg}, \mathrm{Co})$ perovskites used as catalyst precursor, Applied Catalysis A: General, 334 (2008) 251-258.

[6] J. Guo, H. Lou, H. Zhao, D. Chai, X. Zheng, Dry reforming of methane over nickel catalysts supported on magnesium aluminate spinels, Applied Catalysis A: General, 273 (2004) 75-82.

[7] F. Solymosi, P. Tolmacsov, T.S. Zakar, Dry reforming of propane over supported Re catalyst, Journal of Catalysis, 233 (2005) 51-59.

[8] R. Burch, A.J. Mitchell, The role of tin and rhenium in bimetallic reforming catalysts, Applied Catalysis, 6 (1983) 121-128.

[9] N. Viswanadham, R. Kamble, A. Sharma, M. Kumar, A. Saxena, Effect of Re on product yields and deactivation patterns of naphtha reforming catalyst, Journal of Molecular Catalysis A: Chemical, 282 (2008) 74-79.

[10] J. Claridge, M. Green, S. Tsang, Methane conversion to synthesis gas by partial oxidation and dry reforming over rhenium catalysts, Catalysis today, 21 (1994) 455460. 
[11] V. Meille, Review on methods to deposit catalysts on structured surfaces, Applied Catalysis A: General, 315 (2006) 1-17.

[12] B. Mitra, X. Gao, I.E. Wachs, A. Hirt, G. Deo, Characterization of supported rhenium oxide catalysts: effect of loading, support and additives, Physical Chemistry Chemical Physics, 3 (2001) 1144-1152.

[13] D. Neagu, T.-S. Oh, D.N. Miller, H. Ménard, S.M. Bukhari, S.R. Gamble, R.J. Gorte, J.M. Vohs, J.T. Irvine, Nano-socketed nickel particles with enhanced coking resistance grown in situ by redox exsolution, Nature communications, 6 (2015).

[14] D. Neagu, G. Tsekouras, D.N. Miller, H. Ménard, J.T. Irvine, In situ growth of nanoparticles through control of non-stoichiometry, Nature chemistry, 5 (2013) 916923.

[15] J. Deng, H. Dai, H. Jiang, L. Zhang, G. Wang, H. He, C.T. Au, Hydrothermal Fabrication and Catalytic Properties of La1-xSrxM1-yFeyO3 $(\mathrm{M}=\mathrm{Mn}, \mathrm{Co})$ That Are Highly Active for the Removal of Toluene, Environmental Science \& Technology, 44 (2010) 2618-2623.

[16] K.T.C. Roseno, R. Brackmann, M.A. da Silva, M. Schmal, Investigation of $\mathrm{LaCoO} 3, \mathrm{LaFeO} 3$ and $\mathrm{LaCo} 0.5 \mathrm{Fe} 0.5 \mathrm{O} 3$ perovskites as catalyst precursors for syngas production by partial oxidation of methane, International Journal of Hydrogen Energy, 41 (2016) 18178-18192.

[17] R.N. Basu, F. Tietz, O. Teller, E. Wessel, H.P. Buchkremer, D. Stöver, LaNi0.6Fe0.4O3 as a cathode contact material for solid oxide fuel cells, Journal of Solid State Electrochemistry, 7 (2003) 416-420.

[18] S.Q. Chen, Y. Liu, LaFeyNi1-yO3 supported nickel catalysts used for steam reforming of ethanol, International Journal of Hydrogen Energy, 34 (2009) 47354746. 
[19] S.M. de Lima, J.M. Assaf, Ni-Fe Catalysts Based on Perovskite-type Oxides for Dry Reforming of Methane to Syngas, Catalysis Letters, 108 (2006) 63-70.

[20] A. Eyssler, P. Mandaliev, A. Winkler, P. Hug, O. Safonova, R. Figi, A. Weidenkaff, D. Ferri, The Effect of the State of Pd on Methane Combustion in PdDoped LaFeO3, The Journal of Physical Chemistry C, 114 (2010) 4584-4594.

[21] L. Kapokova, S. Pavlova, R. Bunina, G. Alikina, T. Krieger, A. Ishchenko, V. Rogov, V. Sadykov, Dry reforming of methane over $\mathrm{LnFe} 0.7 \mathrm{Ni} 0.3 \mathrm{O} 3-\delta$ perovskites: Influence of Ln nature, Catalysis Today, 164 (2011) 227-233.

[22] U. Oemar, P.S. Ang, K. Hidajat, S. Kawi, Promotional effect of Fe on perovskite LaNixFe1-xO3 catalyst for hydrogen production via steam reforming of toluene, International Journal of Hydrogen Energy, 38 (2013) 5525-5534.

[23] G. Pecchi, P. Reyes, R. Zamora, L.E. Cadús, J.L.G. Fierro, Surface properties and performance for VOCs combustion of $\mathrm{LaFe1-yNiyO3}$ perovskite oxides, Journal of Solid State Chemistry, 181 (2008) 905-912.

[24] H. Provendier, C. Petit, J.L. Schmitt, A. Kiennemann, C. Chaumont, Characterisation of the solid solution $\mathrm{La}(\mathrm{Ni}, \mathrm{Fe}) \mathrm{O} 3$ prepared via a sol-gel related method using propionic acid, Journal of Materials Science, 34 (1999) 4121-4127.

[25] A. Tsoukalou, Q. Imtiaz, S.M. Kim, P.M. Abdala, S. Yoon, C.R. Müller, Dryreforming of methane over bimetallic $\mathrm{Ni}-\mathrm{M} / \mathrm{La} 2 \mathrm{O} 3(\mathrm{M}=\mathrm{Co}, \mathrm{Fe})$ : The effect of the rate of $\mathrm{La} 2 \mathrm{O} 2 \mathrm{CO} 3$ formation and phase stability on the catalytic activity and stability, Journal of Catalysis, 343 (2016) 208-214.

[26] E.-h. Yang, Y.-s. Noh, S. Ramesh, S.S. Lim, D.J. Moon, The effect of promoters in $\mathrm{La} 0.9 \mathrm{M} 0.1 \mathrm{Ni} 0.5 \mathrm{Fe} 0.5 \mathrm{O} 3(\mathrm{M}=\mathrm{Sr}, \mathrm{Ca})$ perovskite catalysts on dry reforming of methane, Fuel Processing Technology, 134 (2015) 404-413. 
[27] Z. Zhong, K. Chen, Y. Ji, Q. Yan, Methane combustion over B-site partially substituted perovskite-type $\mathrm{LaFeO} 3$ prepared by sol-gel method, Applied Catalysis A: General, 156 (1997) 29-41.

[28] J. Fernandes, D. Melo, L. Zinner, C. Salustiano, Z. Silva, A. Martinelli, M. Cerqueira, C.A. Junior, E. Longo, M. Bernardi, Low-temperature synthesis of singlephase crystalline LaNiO 3 perovskite via Pechini method, Materials Letters, 53 (2002) $122-125$

[29] G.S. Gallego, C. Batiot-Dupeyrat, J. Barrault, E. Florez, F. Mondragón, Dry reforming of methane over LaNi1-yByO3 $\pm \delta(\mathrm{B}=\mathrm{Mg}, \mathrm{Co})$ perovskites used as catalyst precursor, Applied Catalysis A: General, 334 (2008) 251-258.

[30] S. Singh, D. Zubenko, B.A. Rosen, Influence of LaNiO3 shape on its solid-phase crystallization into coke-free reforming catalysts, ACS Catalysis, (2016).

[31] J. Okal, W. Tylus, L. Kępiński, XPS study of oxidation of rhenium metal on $\gamma$-Al 2 O 3 support, Journal of Catalysis, 225 (2004) 498-509.

[32] E.S. Shpiro, V.I. Avaev, A. G.V., R. M.A., M. Kh.M., XPS studies of the rhenium state in supported Re catalysts, Journal of Catalysis, 55 (1978) 402-406.

[33] U. Oemar, P. Ang, K. Hidajat, S. Kawi, Promotional effect of Fe on perovskite LaNi x Fe 1- x O 3 catalyst for hydrogen production via steam reforming of toluene, International Journal of Hydrogen Energy, 38 (2013) 5525-5534.

[34] A. Baszczuk, B. Dabrowski, S. Kolesnik, O. Chmaissem, M. Avdeev, Structural and physical properties of Re substituted B-site ordered and disordered SrCo 1- $\mathrm{x} \operatorname{Re}$ x O $3-\delta(x=0.1,0.25,0.5)$, Journal of Solid State Chemistry, 186 (2012) 240-246.

[35] B. Raveau, A. Maignan, C. Martin, M. Hervieu, Re and Ru induced CMR effect in CaMnO 3: the prime role of valency, Materials research bulletin, 35 (2000) 15791585. 
[36] L. Troncoso, M.C. Gardey, M.T. Fernández-Díaz, J.A. Alonso, New RheniumDoped SrCo1- xRexO3- $\delta$ Perovskites Performing as Cathodes in Solid Oxide Fuel Cells, Materials, 9 (2016) 717.

[37] H. Chen, H. Yu, F. Peng, G. Yang, H. Wang, J. Yang, Y. Tang, Autothermal reforming of ethanol for hydrogen production over perovskite LaNiO3, Chemical Engineering Journal, 160 (2010) 333-339.

[38] K. Urasaki, Y. Sekine, S. Kawabe, E. Kikuchi, M. Matsukata, Catalytic activities and coking resistance of $\mathrm{Ni} /$ perovskites in steam reforming of methane, Applied Catalysis A: General, 286 (2005) 23-29.

[39] P.J. Chupas, K.W. Chapman, C. Kurtz, J.C. Hanson, P.L. Lee, C.P. Grey, A versatile sample-environment cell for non-ambient X-ray scattering experiments, Journal of Applied Crystallography, 41 (2008) 822-824.

[40] S.M. Lima, J.M. Assaf, Ni-Fe Catalysts Based on Perovskite-type Oxides for Dry Reforming of Methane to Syngas, Catalysis Letters, 108 (2006) 63-70.

[41] H. Arandiyan, J. Li, L. Ma, S.M. Hashemnejad, M.Z. Mirzaei, J. Chen, H. Chang, C. Liu, C. Wang, L. Chen, Methane reforming to syngas over LaNixFe1-xO3 $(0 \leq \mathrm{x} \leq 1)$ mixed-oxide perovskites in the presence of $\mathrm{CO} 2$ and $\mathrm{O} 2$, Journal of Industrial and Engineering Chemistry, 18 (2012) 2103-2114.

[42] H. Provendier, C. Petit, J.-L. Schmitt, A. Kiennemann, C. Chaumont, Characterisation of the solid solution $\mathrm{La}(\mathrm{Ni}, \mathrm{Fe}) \mathrm{O} 3$ prepared via a sol-gel related method using propionic acid, Journal of Materials Science, 34 (1999) 4121-4127.

[43] E. Bontempi, C. Garzella, S. Valetti, L.E. Depero, Structural study of LaNixFe1-xO3 prepared from precursor salts, Journal of the European Ceramic Society, 23 (2003) 2135-2142. 
[44] J.M. Tascón, J.L.G. Fierro, L.G. Tejuca, Physicochemical properties of LaFeO 3. Kinetics of reduction and of oxygen adsorption, Journal of the Chemical Society, Faraday Transactions 1: Physical Chemistry in Condensed Phases, 81 (1985) 23992407.

[45] H. Fang, Z. Kun, Z. HUANG, W. Guoqiang, L. Haibin, Synthesis of threedimensionally ordered macroporous $\mathrm{LaFeO} 3$ perovskites and their performance for chemical-looping reforming of methane, Chinese Journal of Catalysis, 34 (2013) 1242-1249.

[46] K. Sutthiumporn, T. Maneerung, Y. Kathiraser, S. Kawi, CO2 dry-reforming of methane over $\mathrm{La} 0.8 \mathrm{Sr} 0.2 \mathrm{Ni0} .8 \mathrm{M} 0.2 \mathrm{O} 3$ perovskite $(\mathrm{M}=\mathrm{Bi}, \mathrm{Co}, \mathrm{Cr}, \mathrm{Cu}, \mathrm{Fe})$ : Roles of lattice oxygen on $\mathrm{C}-\mathrm{H}$ activation and carbon suppression, International Journal of Hydrogen Energy, 37 (2012) 11195-11207.

[47] C. Batiot-Dupeyrat, G. Valderrama, A. Meneses, F. Martinez, J. Barrault, J. Tatibouët, Pulse study of $\mathrm{CO} 2$ reforming of methane over LaNiO 3, Applied Catalysis A: General, 248 (2003) 143-151.

[48] S.R. Bare, S.D. Kelly, F. D.Vila, E. Boldingh, E. Karapetrova, J. Kas, G.E. Mickelson, F.S. Modica, N. Yang, J.J. Rehr, Experimental (XAS, STEM, TPR, and XPS) and Theoretical (DFT) Characterization of Supported Rhenium Catalysts, The Journal of Physical Chemistry C, 115 (2011) 5740-5755.

[49] B.A. Rosen, E. Gileadi, N. Eliaz, Electrodeposited Re-promoted Ni foams as a catalyst for the dry reforming of methane, Catalysis Communications, 76 (2016) 2328.

[50] H. Provendier, Steam reforming of methane on LaNixFe1-xO3 $(0<\mathrm{x}<1)$ perovskites. Reactivity and characterisation after test

Chemistry, 4 (2001) 57-66. 
[51] L. Guczi, G. Stefler, O. Geszti, I. Sajó, Z. Pászti, A. Tompos, Z. Schay, Methane dry reforming with CO 2: a study on surface carbon species, Applied Catalysis A: General, 375 (2010) 236-246.

[52] J.R. Rostrup-Nielsen, J. Sehested, Whisker Carbon Revisited, in: G.W.R. J.J. Spivey, B.H. Davis (Eds.) Studies in Surface Science and Catalysis, Elsevier2001, pp. $1-12$.

[53] A. Cimino, B. De Angelis, D. Gazzoli, M. Valigi, Photoelectron spectroscopy (XPS) and thermogravimetry (TG) of pure and supported rhenium oxides 1. Pure rhenium compounds, Zeitschrift für anorganische und allgemeine Chemie, 460 (1980) 86-98.

[54] A. Naor, N. Eliaz, L. Burstein, E. Gileadi, Direct experimental support for the catalytic effect of iron-group metals on electrodeposition of rhenium, Electrochemical and Solid-State Letters, 13 (2010) D91-D93. 


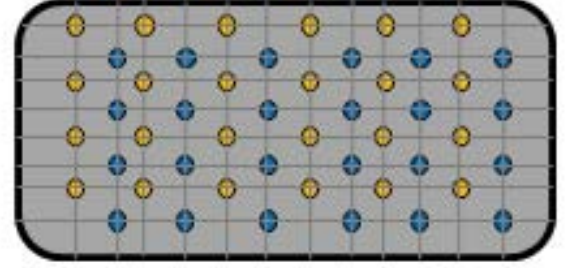

$\mathrm{LaFe}_{0.6} \mathrm{Ni}_{0.2} \mathrm{Re}_{x} \mathrm{O}_{3+\delta}$ precursor

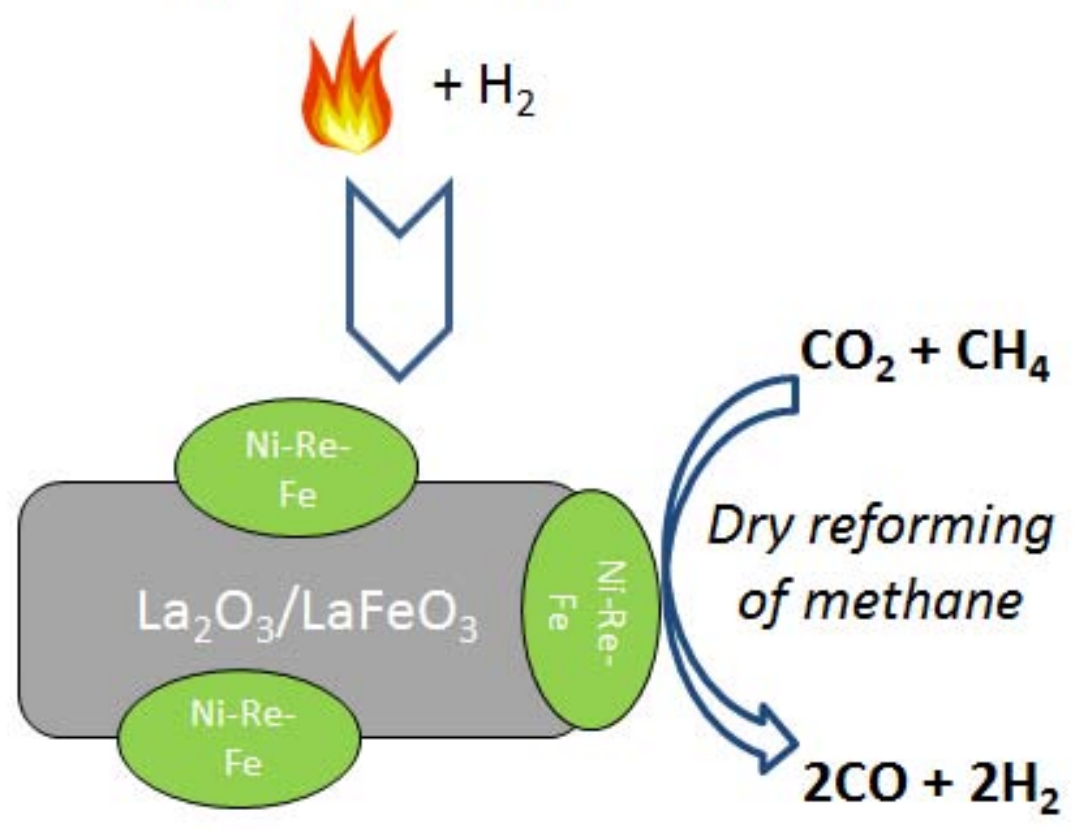

$\mathrm{Ni}$-Re-Fe alloy crystallization 